\title{
Social comparison and life satisfaction in social media: The role of mattering and state self-esteem
}

\author{
Patrick P. T. Sim, Kususanto Prihadi
}

Department of Psychology, HELP University, Malaysia

\begin{tabular}{l}
\hline \hline Article Info \\
\hline Article history: \\
Received May 8, 2020 \\
Revised Jun 10, 2020 \\
Accepted Jul 8, 2020 \\
\hline
\end{tabular}

\section{Keywords:}

Mattering

State self-esteem

Social comparison

Life satisfaction

\begin{abstract}
The overarching aim of this study is to explain how comparing self to others in social media might predict one's sense of life satisfaction. In order to achieve that, we test the hypothesis that mattering and state self-esteem play a serial mediation that explains the link between social comparison in social media and life satisfaction. One hundred and forty-seven participants' ages between 18 to 35 were recruited to participate in this research and were asked to fill up the Iowa-Netherlands Comparison Orientation Measure, General Mattering Scale, State Self-Esteem Scale and Riverside Life Satisfaction Scale questionnaires. Bias-free Bootstrap Method with 5000 sample has been conducted to analyze the relationship among the variables, and the results suggested that the overall model of the predictor significantly contributed to life satisfaction. Nevertheless, because social comparison did not predict the sense of mattering, serial mediation did not occur as per hypothesized. Our supplementary analyses indicated that state self-esteem fully mediated the contribution of mattering on life satisfaction. Implication, limitation and suggestions are discussed at the end of the paper.
\end{abstract}

This is an open access article under the CC BY-SA license.

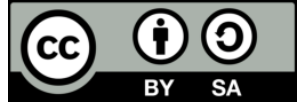

Corresponding Author:

Kususanto Prihadi,

Department of Psychology,

Higher Education Learning Philosophy (HELP) University,

Selangor, Malaysia.

Email: prihadi.k@help.edu.my

\section{INTRODUCTION}

Life satisfaction was strongly associated with mental health, even after simultaneously considering factors such as income, general health, and gender [1]. Out of many factors that have been reported to predict mental health, one of the most recently studied is the usage of social media, or social network sites (SNS) [2-6]. The phenomenon was observed due to the drastic increase of the mobile phone usage around the world. Undeniably, mobile phones has help revolutionised the way people are communicating with one another, and within the last decade, it has been a primary choice for interpersonal relationship, one of the few mediums that is driving the increase of smartphone usage is SNS like Facebook, Twitter, Instagram, WhatsApp, and many others [7]. The phenomenon leads us to an exponential growth of the usage of social media, or also called social networking sites (SNS) because of its preferable communicational and informational functionalities [8], making face-to-face interactions less favourable [9]. And with the emergence of digital media society, it was supposedly created for the dream of having a more connected world, a virtual platform where everyone could share their stories, thoughts, experiences, and feel less ostracised. However, as SNS began to permeate into almost every aspect of our lives [10], it also subconsciously began to shape us in accordance to "Media morality", which ensue us into conceptualising and taking into consideration seemingly pleasing methods of acting towards others, and this is especially prominent during the early years of our youth [11]. 
Based on various past studies, the more individuals interact through SNS, the higher the tendency for overexploitation, which has shown to significantly alter the individuals' perceived life satisfaction [4, 12]. However, humans are just inherently social beings [13], always chasing for that desirable sense of being longed for, and SNS becomes that avenue for that; moreover, SNS allow their users to portray themselves through the making of their own electronic persona, detailing their personal information, expressing their beliefs, emotions and personal preferences belongingness [14-16], or basically, granting them the ability to be whoever their hearts desire. As of today, the functionality of SNS is progressively being utilized for social comparison intents [17], and this is triggered by the magnitude of content available at their fingertips [18-22]. One of the research conducted by IBM, showed that there is an estimated that 2.5 quintillion bytes of data that are being generated on a daily basis and SNS contributes a massive volume of the data [23]. As the development of social media radically evolves, the greater the influence it has on the way people communicate and acquire information [24].

In turn, it opened up a gateway for unflattering social comparison among SNS users, because of how easily they can render their online persona [25]. Individuals tend to openly exaggerate the content they upload on their profile, depicting how flawless and happy they are, and therefore, making the information positively skewed favoring the user [26, 25], which will always compromise of exclusive information that subsequently leads to social comparisons [26-31]. Also, multiple studies has suggested that purposive social comparison has been linked to poorer well-being [32] and the individuals' life satisfaction [3, 4, 12, 33, 34].

With the magnitude of information so easily accessed, people tend to either knowingly or unknowingly browse social comparison sites for the social comparative purposes [17] to develop their selfesteem or self-enhancement [35-37], and this becomes even more prevalent when the social interactions is amongst friends and family, as they share similar comparison standards [32]. Based on the 'sociometer theory' [38], self-esteem contributes in sustaining interpersonal relationships by monitoring the reactions of others and then reciprocate accordingly to maintain that successful relationship [39]. Social networking giants very subtly provides one-click tools such as "Likes", "Tag" and "Share" that was supposedly to help improve interactions [40-42]; however, it becomes a quantifiable outlet for comparisons of oneself with one another, comparing the amount of "Likes", "Tag" and "Share" they have [32]. With every accumulation of desirable likes received on their social networking profiles, it heightens their sense of social capital and creates this perceptions of prestige, which considerably makes social networking site an independent variable of selfesteem, despite some studies reported negative correlations between self-esteem and social comparison tendencies on SNS [20, 43, 44].

On the other hand, studies shows that it evident that one's general self-esteem will not be significantly affected by their short-termed social comparison, yet it will temporarily fluctuate as the social comparison takes place [19, 45-47]. The temporary fluctuation of self-esteem state is addressed as state self-esteem [48], and in a relatively recent study, correlation between SNS usage and state self-esteem has been reported [27], because of how state self-esteem is a momentary shift in a person's feelings about themselves [49], whereby the fluctuation is dependent on the extent of how others currently value their ongoing relationship with others [38]. Accordingly, it was also reported that individuals with higher intent to browse SNS reported lower levels of state self-esteem, right before they started browisng [27].

In line with that, short term exposures to particular content would only affect state self-esteem [45], instead of their trait (general) self-esteem [19, 46, 47]. Furthermore, considerable significance on the link state self-esteem and life satisfaction was as well be reported, as people subconsciously consume information such as pictures of recent vacations, posting bragging about expensive material possessions, it tends to trigger invidious emotions as viewers becomes envious, lowering their state self-esteem, which in turn also lowers life satisfaction at current state [29, 50]. Krasnova and his colleagues also concluded with similar outcomes, [29]. Moreover, accumulated impression from others is substantial enough for the growth of one's self-esteem, because people need to have the sense of belonging in society [51]. It is suggested that the development of one's self-esteem coexists with the development of one's sense of mattering, or in other words, one's self-esteem might be increased when they perceive that they matter to people they communicate with, the more they feel they matter, the higher their state self-esteem fluctuates, as well as their overall well-being [39, 52-56].

Mattering refers to the feeling that others depend on us, are interested in us, are connected with our fate, or experience us as an ego-extension [57]. Two types of mattering were reported, they are societal and interpersonal mattering $[52,58]$, societal mattering comprises of how one's contributions will bring forth changes in the social environment, whereas interpersonal mattering refers to the significance of the individual to the people around them [59]. In a study by Moksnes and Espnes's [60], it was reported that self-esteem was not only moulded by the individuals' appraisals of themselves, but also to what degree they matter to the people around them [61-63]. In other words, social comparison in SNS will change the way they feel how much they matter for others, and that feeling will eventually alter their evaluation of themselves, hence the state self-esteem changes [39, 52- 56]. Afterwards, their altered state self-esteem would contribute 
to their life satisfaction [27, 31, 45-47, 50]. Studies have reported the direct link between SNS usage and life satisfaction [2- 6], however, there was not a clear understanding about the mechanism behind the relationship [64]. On top of that, there are various past studies that has a different outlook on how life satisfaction is influenced [64]. There are various extrinsic and intrinsic factors which seems to be possible influences on life satisfaction, such as social health, general health and marital status [65], loneliness [66, 67] timidity [44, 68, 69], living standards [70], and also social networking consumption [3, 4, 6, 71]. With SNS accessible, people can socially compare themselves to others in terms of the aforementioned factors easily and develop their social envy [29].

The aforementioned studies indicated that the SNS usage directly predict the life satisfaction among its users. Nevertheless, other variables such as mattering and state self-esteem were also reported to play their roles in developing the life satisfaction among SNS users, and most of the literature we reviewed suggested that the aforementioned two variables might be able explain the link between SNS usage and life satisfaction. In other words, we hypothesize that the engagement of SNS users in social comparison might alter the way they feel they matter to others, and therefore they value themselves higher or lower at the moment. In turn, this momentary self-evaluation, or state self-esteem, will alter the way they are satisfied with their life. Thus, a serial mediation as illustrated in Figure 1 is hypothesized and is tested.

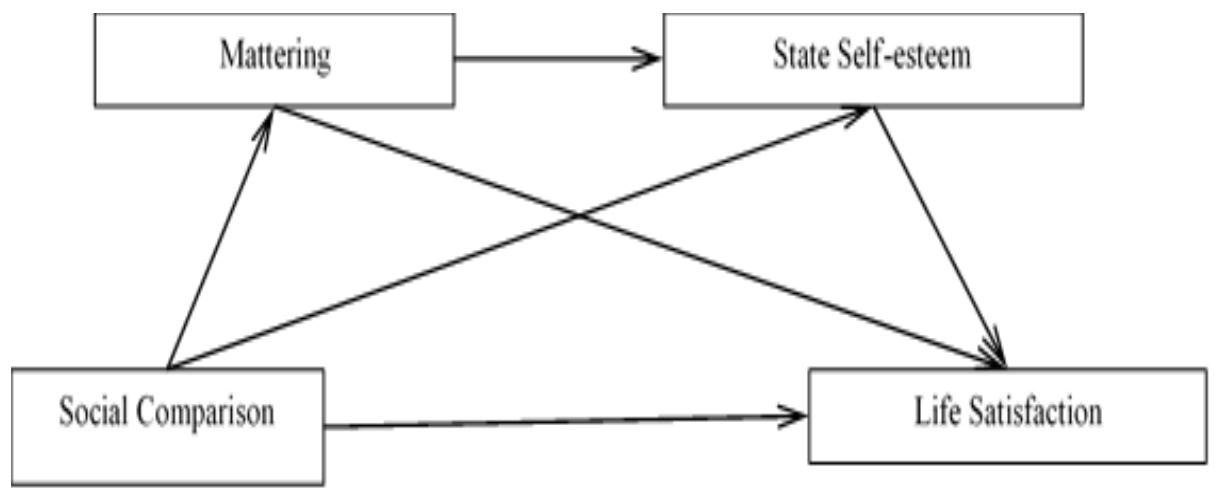

Figure 1. Hypothetical model of the serial mediating role of mattering and state self-esteem on the relationship between social comparison in social networking site and life satisfaction

The hypothetical serial media ton model illustrated in Figure 1 shows the hypothesized relationships among the variables in the present study. Therefore, data were collected in order to test the following hypotheses:

a. Social comparison as a model predicts life satisfaction.

b. Social comparison predicts life satisfaction after controlling for mattering and state self-esteem.

c. Mattering mediates the contribution of social comparison to life satisfaction.

d. State self-esteem mediates the relationship between social comparisons to life satisfaction.

e. Mattering and state self-esteem mediates the relationship between social comparison and life satisfaction.

\section{REASERCH METHOD}

\subsection{Design}

This study is conducted as a qualitative survey. Social comparison is placed as predictor, and the outcome variable is Life Satisfaction. Two mediators are analyzed in a serial manner in this study, namely Mattering and State Self-esteem. Social comparison is operationally defined as the total score on the 11 statement on the Iowa-Netherlands Comparison Orientation Measure test (INCOM; Gibbons and Buunk, 1999), whereby a higher score indicates higher social comparison, measured on a 5-point Likert scale. The operational definition for mattering is the total score on the General Mattering Scale (GMS; Sari and Karaman, 2018), whereby the higher score indicates higher level of perception of mattering, measured on a 4-point Likert scale. State self-esteem is operationally defined as the total score on the State Self-esteem Scale (SSES; Heatherson and Polivy, 1991), whereby the higher the score indicates higher state self-esteem, measured on a 5-point Likert scale. Life satisfaction is operationally defined as the total score on the Riverside Life Satisfaction Scale (RLSS; Margolis, Schwitzgebel, Ozer and Lyubomirsky, 2018), whereby the higher score indicates higher level of life satisfaction. 


\subsection{Participants}

One hundred and nineteen participants have been gathered through purposive haphazard sampling method through social media such as Facebook, Instagram and WhatsApp, and referrals. The suggested sample size by G-power analysis with effect size of 0.15 and a power of 0.95 was 103 . In order for the participants to be eligible, they would have to be 18 years old and above with an active social networking site account or accounts within one-year time frame. When they would like to volunteer themselves in responding the data, they would click the link provided in social media and enter their responses. The participants were also asked to share the Google form link to people around them. Because purposive haphazard sampling might result to less normality of data distribution, we utilized Bootstrap method in order to perform the hierarchical multiple regression analyses among the variables; Bootstrap method is considered one of the most robust method in dealing with data without normal distribution due to its nature of randomizing every data to each other. In our case, we set the sampling to be 5000, which means that the method has randomized 5000 possible links within our samples.

\subsection{Procedures and analysis method}

Participants were informed that they would be participating in an online survey regarding their SNS usage. They were given a link, which led them to a Google form with the online survey. The whole set of the scales took approximately fifteen minutes to twenty minutes to complete. An informed consent form was presented before the study begins to protect the rights and well-being of the participants. Upon completion of the survey, the participants were thanked for their participation. Data analyses were conducted by utilizing PROCESS, an extension of SPSS. Model 6 for serial mediation with two mediators and 5000 sample were chosen due to the fitness of the analysis. The data collection procedure has approved by the ethic review board (ERB) of the Department of Psychology, HELP Univeristy through a stringent scrutiny before it was approved and applied to our participants.

\section{RESULTS AND DISCUSSION}

Hierarchical multiple regression was chosen to be used to analyze the data through Bootstrap test using PROCESS Macro Model 6. However, before the Bootstrap test using PROCESS Macro Model 6 was conducted, the reliability of the scale was checked and is shown in the Table 1 . The table shows the Cronbach's Alpha of all the four scales, Iowa-Netherlands Comparison Orientation Measure $(\alpha=0.61)$, General Mattering Scale $(\alpha=0.82)$, State Self-Esteem Scale $(\alpha=0.88)$ and Riverside Life Satisfaction Scale $(\alpha=0.8)$. However, the Iowa-Netherlands Comparison Orientation Measure was only reliable after the exclusions of items 5, 6, 10 and 11 .

Table 1. Reliability analysis of scale

\begin{tabular}{ll}
\hline Scale & Cronbach's Alpha \\
\hline Iowa-Netherlands Comparison Orientation Measure & 0.61 \\
General Mattering Scale & 0.82 \\
State Self-Esteem Scale & 0.88 \\
Riverside Life Satisfaction Scale & 0.8 \\
\hline
\end{tabular}

\subsection{Results of the hypotheses testing}

Our first hypothesis was supported by the results of the analysis by utilizing PROCESS Macro Model 6 showed that the overall model of social comparison, mattering and state self-esteem significantly predicted life satisfaction, $\mathrm{F}(3,143)=20.59, \mathrm{p}<0.001$, accounting for $30 \%$ of the variances in the outcome, $\mathrm{R}^{2}=0.30$. We hypothesized that social comparison predicts life satisfaction after controlling for mattering and state self-esteem, and it was not supported by our findings. Social comparison was not a significant predictor of life satisfaction while controlling for mattering and state self-esteem, $b=-0.26, t(146)=-1.87, p=0.063$. The result indicated that the results of this current study do not support the second hypothesis.

Another unsupported hypothesis of ours was that mattering mediates the contribution of social comparison to life satisfaction. A biased-corrected bootstrapped confidence interval using 5000 samples revealed that there was no significant indirect effect of social comparison on life satisfaction through mattering $(\beta=0.01, B c a C I[-0.018,0.071])$, suggesting that no mediation occurred. Our fourth hypothesis was that state self-esteem mediates the relationship between social comparisons to life satisfaction. The biased-corrected bootstrapped confidence interval using 5000 samples revealed that there was no significant indirect effect of social comparison on life satisfaction through state self-esteem, $(\beta=0.02, B c a C I[-0.135,0.186])$, suggesting that no mediation occurred, hence our fourth hypothesis was not supported. 
Another biased-corrected bootstrapped confidence interval using 5000 samples was utilized in order to test our fifth hypothesis, whether mattering and state self-esteem perform serial mediation on the relationship between social comparison and life satisfaction. The results revealed that there was no significant indirect effect of social comparison on life satisfaction through mattering through state self-esteem, $\quad(\beta=0.03, B$ caCI $[-0.033,0.103])$, suggesting that serial mediation did not occur. Figure 2 and Table 2 summarize the results and the findings of this current study. Table 2 depicts the summary of the total effect and indirect effects report by the PROCESS Macro Model 6.

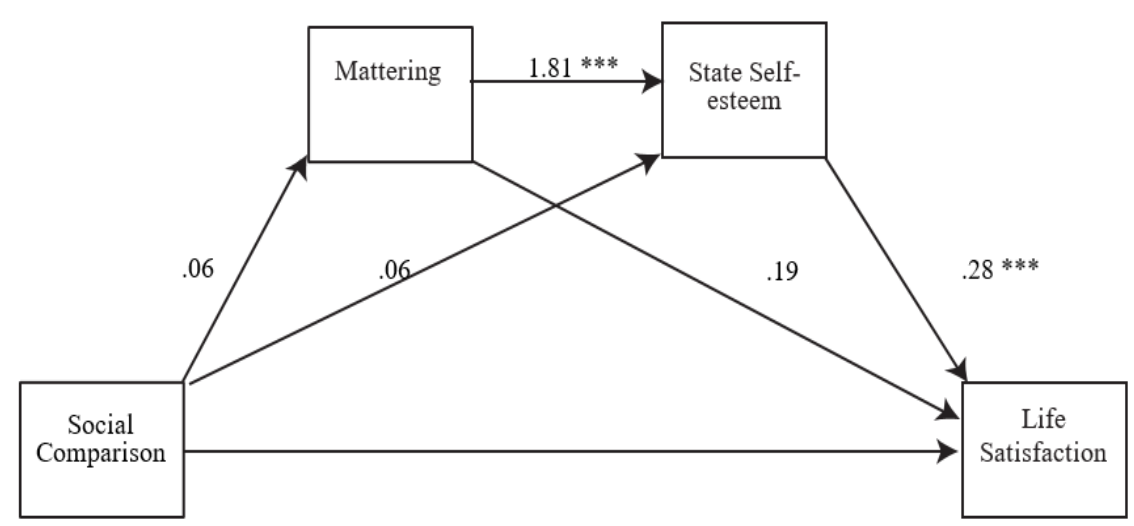

Figure 2. Summary of the serial mediation model

Table 2. Serial mediation of mattering and state self-esteem indirect effect of $\mathrm{X}$ on $\mathrm{Y}$

\begin{tabular}{lllll}
\hline & Effect & BootSE & BootLLCI & BootULCI \\
\hline Total & .06 & .10 & -.1291 & .2582 \\
Indirect 1 & .01 & .02 & -.0184 & .0714 \\
Indirect 2 & .02 & .08 & -.1349 & .1857 \\
Indirect 3 & .03 & .03 & -.0326 & .1033 \\
\hline
\end{tabular}

Additionally, we ran another supplementary analysis because the findings showed that mattering was a significant predictor of state self-esteem, and state self-esteem was a significant predictor of life satisfaction. The supplementary analysis was conducted to investigate whether mattering actually predict life satisfaction through state self-esteem. Hierarchical multiple regression was used again to analyze the data through Bootstrap test using PROCESS Macro Model 4 and below is summary of the findings in Figure 2 and Table 3. Figure 3 and Table 3 summarize the results and the findings of this current study.

Note: $p<.001 * * *$

Note: $p<.001 * * *$

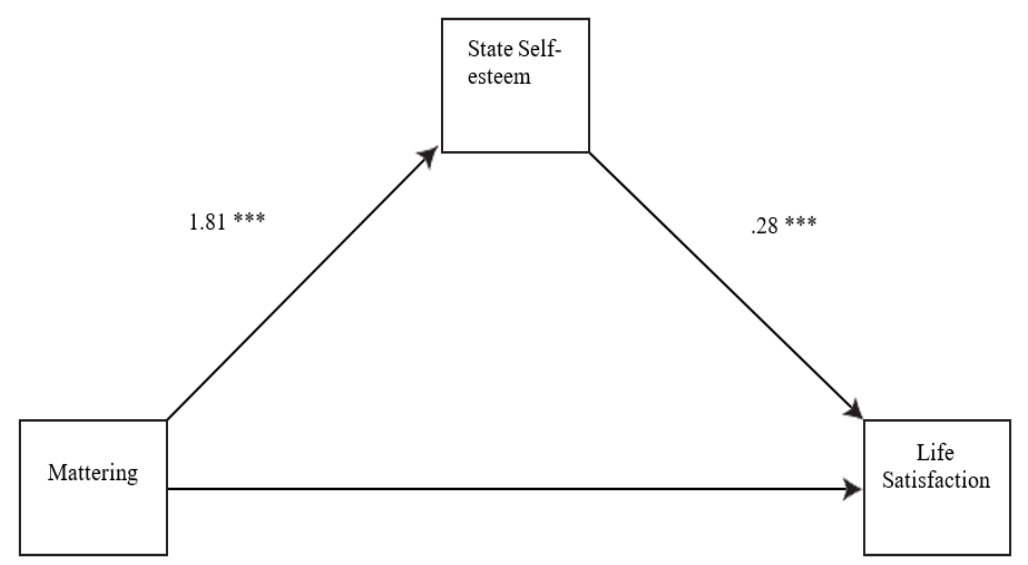

Figure 3. Mediation role of state self-esteem on the association between mattering and life satisfaction 
Table 3 depicts the summary of the total effects, direct effects and indirect effects report by the PROCESS Macro Model 4. The overall model of mattering significantly predicted life satisfaction, $F(1,145)=12.56, p=0.001$, accounting for $8 \%$ of the variances in the outcome, $\mathrm{R}^{2}=0.80$. Mattering significantly predicted life satisfaction, $\mathrm{b}=0.67, t(145)=3.54, p=0.001$. Based on the Table 3 above, a biased-corrected bootstrapped confidence interval using 5000 samples revealed that there was a significant indirect effect of mattering on life satisfaction through state self-esteem, Beta $=0.50$, as the biased-corrected bootstrapped confidence interval did not contain zero, Bca CI [0.290, 0.734], suggesting that there was a mediating effect of state self-esteem on the relationship between mattering and life satisfaction.

A multiple regression analysis was conducted in order to support the aforementioned results, and it was discovered that despite the overall model mattering significantly predicted life satisfaction, $F(2,144)=28.64, p<0.001$, accounting for $28.5 \%$ of the variances in the outcome, $\mathrm{R}^{2}=.29$. State self-esteem significantly predicted life satisfaction when controlling for mattering, $b=.28, t(144)=6.42, p<0.001$. Interestingly, mattering is no longer a significant predictor of life satisfaction when controlling for state self-esteem, $b=.17, t(144)=.92, p=0.358$. In other words, state self-esteem explained the link between mattering and life satisfaction.

Table 3. Mediation of state self-esteem, total, direct and indirect effect of $\mathrm{X}$ on $\mathrm{Y}$

\begin{tabular}{lllll}
\hline & Effect & BootSE & BootLLCI & BootULCI \\
\hline Total & 0.67 & 0.19 & 0.296 & 1.041 \\
Direct & 0.17 & 0.18 & -0.194 & 0.534 \\
Indirect & 0.50 & 0.11 & 0.046 & -.734 \\
\hline
\end{tabular}

\section{DISCUSSION}

Our findings suggested that serial mediation of mattering and state self-esteem on the link between social comparison in SNS and life satisfaction did not occur. In other words, comparing ourselves with other people through SNS does not significantly increase or decrease our sense of life satisfaction. Nevertheless, more important finding was shown in our supplementary analysis, where we discovered that state self-esteem can explain the significant link between mattering and life satisfaction; when one senses that they matter to other, they will not feel satisfied with their life until they evaluate themselves positively.

Results of the analysis indicated that the model of social comparison in SNS is a significant predictor of life satisfaction. The findings of this study is in line with multiple past study that also showed significant relationship between the both variables [2-4, 12, 20, 29, 33, 34].

A Study by Rosenthal-von der Pütten and his colleagues [32] supports the finding of this current study. The similarity of the results was highly likely because the nature of how their study was ran. They made their participants compare a selfie picture of themselves and a selfie picture of another person's in terms of likes. They concluded that when there is excessive SNS, in subsequently also increases the opportunities for unflattering comparisons in terms of pictures of recent vacations, expensive material possessions, numbers of Likes and etc [40-42]. They were using similar context with this current study; therefore, the findings aligned with each other.

Results from this study depicted that social comparison in SNS was no longer a significant predictor for life satisfaction when controlling for mattering and state self-esteem. Which means that comparing oneself with others through SNS will not change their perception until they developed the sense of mattering and a positive self-evaluation. In line with that, Lee [30], as well as de Vries and Kuhne [72], which suggested that social comparisons alone was not a robust enough predictor of life satisfaction. Similarly, Wang and his colleagues [44], also suggested that social comparisons to affect life satisfaction, it would first have to affect the individuals' self-esteem.

Furthermore, it was depicted that before an individual 'decided' to value themselves positive or negative, they need to have a certain sense of mattering that will guide them to make their 'decision' [52, 61, 63]. In the light of that, a more recent study by Cha [39] has shared some light that mattering has to coexist with self-esteem, and it was further elaborated that mattering is a preceding factor before self-esteem. Therefore, state self-esteem and mattering tend to coexist in predicting another variable. The similarity in terms of the findings is mainly due to the fact that all their participants were users of SNS and that one of their variables used was also social comparison.

Results of our supplementary analysis showed that state self-esteem was able to significantly predict life satisfaction. This was in line with the studies done by Bozorgpour and Salimi [50], and also Krasnova and his colleagues [29], who reported that life satisfaction would only be altered when state self-esteem of an

Int. J. Public Health Sci, Vol. 9, No. 3, September 2020: 245 - 254 
individual was altered by their sense of matterin. These results depicted that the contribution of mattering on life satisfaction can be explained by state self-esteem. Which means when an individual sense that they are mattered to the people around them, their state of self-esteem would improve, and that would subsequently make improvements to their life satisfaction as well.

\subsection{Limitations}

One limitation of the study lies on the size of the sample for the study, the reason being is due to the fact that the $\mathrm{G}^{*}$ power analysis was not set to the minimum power. On top of that, although we are present in a generation of new age technological advancement, some of the participants were only exposed to these sort of technology (example: SNS) only in the later parts of their lives. Therefore, measuring gap between age groups might have altered the results of this current study. Also, some of the participants were of different generational cohort, which means their outlook on all the variables tested in this study would vary, further increasing the possibility of altering the findings. In light of this, it would be highly suggested that for future research to take into consideration of these factors in their study. Other than that, it would be also recommended that different scales be utilized to measure both mattering and state self-esteem for future research or a development of new scales that would be able to more closely capture the targeted variable. If future research that will be based on this current finding, it is also high suggested to isolate the type of social comparison (e.g. Upward social comparison, downward social comparison) that might occur.

\subsection{Practical implications}

Based on the supplementary analysis done on the mediating effect of state self-esteem on the relationship between mattering and life satisfaction, it is relatively evident that we should focus our attention to improving one's state self-esteem in order to subsequently improve one's life satisfaction in general. Therefore, it is utmost important for us to improve our state self-esteem, workshops or trainings structured based on the findings of this current study that would be able to target ways to foster and nurture a healthy state self-esteem. Furthermore, the focus should not only be on state self-esteem alone, as mattering also plays a crucial role in effecting life satisfaction. With various past studies depicting correlation between state self-esteem and mattering, workshops or training should be done parallel in improving both state self-esteem and mattering.

\section{CONCLUSION}

After everything that has been discussed, as a conclusion, this study has contributed to literature and theories, results and findings can be used as a foundation for practical implications for the future. Other than that, we can also see the adverse effects of SNS, and how easily any individual can compare and lead to a myriad of unfavourable outcomes. You can argue about the potential benefits of social networking platforms; however, this current study is not trying to persuade you to reduce the usage of SNS, it is merely to show you the possible affects that could occur.

\section{ACKNOWLEDGEMENTS}

This study is fully funded by the Research Management Center of HELP University, Malaysia, through internal research grant scheme (IRGS). This study is a part of a research by the Research Center of Mattering, Cyber psychology and Games, Department of Psychology, HELP University.

\section{REFERENCES}

[1] P. Lombardo, W. Jones, L. Wang, X. Shen and E. M. Goldner, "The fundamental association between mental health and life satisfaction: results from successive waves of a Canadian national survey," BMC Public Health, vol. 18, no. 342, 2018.

[2] A. Błachnio, A. Przepiorka and I. Pantic, "Association between Facebook addiction, self-esteem and life satisfaction: A cross-sectional study," Computers in Human Behaviour, vol. 55, pp. 701-705, 2016.

[3] T. Chan, "Facebook and its Effects on Users' Empathic Social Skills and Life Satisfaction: A Double-Edged Sword Effect," Cyberpsychology, Behaviour, and Social Networking, vol. 17, no. 5, p. 276-280, 2014.

[4] E. Kross, P. Verduyn, E. Demiralp, J. Park, D. S. Lee, N. Lin and O. Ybarra, "Facebook use predicts declines in subjective well-being in young adults," PloS One, vol. 8, no. 8, 2013.

[5] F. McAndrew and H. Jeong, "Who does what on Facebook? Age, sex, and relationship status as predictors of Facebook use," Computers In Human Behaviour, vol. 28, no. 6, pp. 2359-2365, 2012. 
[6] S. Satici and R. Uysal, "Well-being and problematic Facebook use," Computers in Human Behavior, vol. 49, pp. 185-190, 2015.

[7] S. Basu, S. Garg, M. Singh and C. Kohli, "Addiction-like behaviour associated with mobile phone usage among medical students in Delhi," Indian Journal of Psychological Medicine, vol. 40, no. 5, pp. 446-451, 2018.

[8] D. Olenik-Shemesh and T. Heiman, "Cyberbullying Victimization in Adolescents as Related to Body Esteem, Social Support, and Social Self-Efficacy," The Journal of Genetic Psychology, vol. 178, no. 1, pp. 28-43, 2016.

[9] T. M. Dumas, M. Maxwell-Smith, J. P. Davis and P. A. Giulietti, "Lying or longing for likes? Narcissism, peer belonging, loneliness and normative versus deceptive like-seeking on Instagram in emerging adulthood," Computers in Human Behaviour, vol. 71, pp. 1-10, 2017.

[10] L. Zhan, Y. Sun, N. Wang and X. Zhang, "Understanding the influence of social media on people's life satisfaction through two competing explanatory mechanisms," Aslib Journal of Information Management, vol. 68, no. 3, pp. 347-361, 2016.

[11] S. Bengtsson and B. Johansson, "Media Micro-Generations," Nordicom Review, vol. 39, no. 2, pp. 95-100, 2018.

[12] P. Verduyn, D. S. Lee, J. Park, H. Shablack, A. Orvell, J. Bayer and E. Kross, "Passive facebook usage undermines affective well-being: Experimental and longitudinal evidence," Journal of Experimental Psychology. General, vol. 144, no. 2, pp. 480-488, 2015.

[13] Y. S. N., "The neurobiology of human social behaviour: an important but neglected topic," Journal of Psychiatry \& Neuroscience, vol. 33, no. 5, pp. 391-392, 2008.

[14] Z. Ivcevic and N. Ambady, "Personality impressions from identity claims on Facebook," Psychology of Popular Media Culture, vol. 1, no. 1, pp. 38-45, 2012.

[15] A. Nadkarni and S. G. Hofmann, "Why do people use Facebook?," Personality and Individual Differences, vol. 52, no. 3, pp. 243-249, 2012.

[16] L. P. Tosun, "Motives for Facebook use and expressing the "true self" on the Internet," Computers in Human Behavior, vol. 28, no. 4, pp. 1510-1517, 2012.

[17] N. Haferkamp and N. C. Kramer, "Social comparison 2.0: Examining the effects of online profiles on socialnetworking sites," Cyberpsychology, Behaviour, and Social Networking, vol. 14, no. 5, pp. 309-314, 2011.

[18] C. Peng, T. Wu, Y. Chen and D. Atkin, "Comparing and modelling via social media: The social influences of fitspiration on male Instagram users' work out intention," Computers In Human Behaviour, vol. 99, pp. 156-167, 2019.

[19] E. A. Vogel, J. P. Rose, L. R. Roberts and K. Eckles, "Social comparison, social media, and self-esteem," Psychology of Popular Media Culture, vol. 3, no. 4, pp. 206-222, 2014.

[20] J. Nesi and M. J. Prinstein, "Using social media for social comparison and feedback seeking: Gender and popularity moderate associations with depressive symptoms," Journal of Abnormal Child Psychology, vol. 43, no. 8, pp. 1-12, 2015.

[21] J. W. Kim and T. M. Chock, "Body image 2.0: Associations between social grooming on Facebook and body image concerns," Computers in Human Behavior, vol. 48, pp. 331-339, 2015.

[22] J. Gerson, A. C. Plagnol and P. J. Corr, "Subjective well-being and social media use: Do personality traits moderate the impact of social comparison on Facebook?," Computers in Human Behavior, vol. 63, pp. 813-822, 2016.

[23] P. Zikopoulos, K. Parasuraman, T. Deutsch, J. Giles and D. Corrigan, "Harness the Power of Big Data the IBM Big Data Platform," New York: McGraw Hill Professional, 2012.

[24] E. Ngai, K. Moon, S. Lam, E. Chin and S. Tao, "Social media models, technologies, and applications: an academic review and case study," Industrial Management \& Data Systems, vol. 115, no. 5, pp. 769-802, 2015.

[25] J. B. Walther, "Selective self-presentation in computer-mediated communication: Hyperpersonal dimensions of technology, language, and cognition," Computers in Human Behaviour, vol. 23, no. 5, pp. 2538-2557, 2007.

[26] H. Appel, A. L. Gerlach and J. Crusius, "The interplay between Facebook use, social comparison, envy, and depression," Current Opinion in Psychology, vol. 9, pp. 44-49, 2016.

[27] Y. Alfasi, "The grass is always greener on my Friends' profiles: The effect of Facebook social comparison on state self-esteem and depression," Personality and Individual Differences, vol. 147, pp. 111-117, 2019.

[28] W. Chen, C.-Y. Fan, Q.-X. Liu, Z.-K. Zhou and X.-C. Xie, "Passive social network site use and subjective wellbeing: a moderated mediation model," Computers in Human Behaviour, vol. 64, pp. 507-514, 2016.

[29] H. Krasnova, H. Wenninger, T. Widjaja and P. Bruxmann, "Envy on Facebook: a hidden threat to users' life satisfaction?," 11th International Conference on Wirtschaftsinformatik, Universität Leipzig, Germany, pp. 1-16, 2013.

[30] S. Y. Lee, "How do people compare themselves with others on social network sites?: The case of Facebook," Computers in Human Behavior, vol. 32, pp. 253-260, 2014.

[31] E. A. Vogel, J. P. Rose, B. M. Okdie, K. Eckles and B. Franz, "Who compares and despairs? The effect of social comparison orientation on social media use and its outcomes," Personality and Individual Differences, vol. 86, pp. 249-256, 2015.

Int. J. Public Health Sci, Vol. 9, No. 3, September 2020: $245-254$ 
[32] A. Rosenthal-von der Pütten, M. Hastall, S. Köcher, C. Meske, T. Heinrich, F. Labrenz and S. Ocklenburg, "“Likes" as social rewards: Their role in online social comparison and decisions to like other People's selfies," Computers In Human Behaviour, vol. 92, pp. 76-86, 2019.

[33] H. Chou and N. Edge, "“They are happier and having better lives than I am": the impact of using Facebook on perceptions of others' lives," Cyberpsychology, Behaviour Social Network, vol. 15, no. 2, pp. 117-121, 2012.

[34] E. Tandoc, P. Ferrucci and M. Duffy, "Facebook use, envy, and depression among college students: Is Facebooking depressing?," Computers in Human Behaviour, vol. 43, pp. 139-146, 2015.

[35] C. L. Gruder, "Determinants of social comparison choices," Journal of Experimental Social Psychology, vol. 7, no. 5 , pp. 473-489, 1971

[36] T. A. Wills, "Downward comparison principles in social psychology," Psychological Bulletin, vol. 90, no. 2, pp. 245-271, 1981.

[37] L. Festinger, "A theory of social comparison processes," Human Relations, vol. 7, pp. 117-140, 1954.

[38] M. Leary, E. Tambor, S. Terdal and D. Downs, "Self-esteem as an interpersonal monitor: The sociometer hypothesis," Journal Of Personality And Social Psychology, vol. 68, no. 3, pp. 518-530, 1995.

[39] M. Cha, "The mediation effect of mattering and self-esteem in the relationship between socially prescribed perfectionism and depression: Based on the social disconnection model," Personality and Individual Differences, vol. 88, pp. 148-159, 2016.

[40] R. Hayes, C. Carr and D. Wohn, "It's the Audience: Differences in Social Support across Social Media," Social Media+Society, vol. 2, no. 4, pp. 1-10, 2016.

[41] R. Hayes, C. Carr and D. Wohn, "One Click, Many Meanings: Interpreting Paralinguistic Digital Affordances in Social Media," Journal of Broadcasting \& Electronic Media, vol. 60, no. 1, pp. 171-187, 2016.

[42] D. Wohn, C. Carr and R. Hayes, "How Affective Is a "Like"?: The Effect of Paralinguistic Digital Affordances on Perceived Social Support," Cyberpsychology, Behavior, And Social Networking, vol. 19, no. 9, pp. 562-566, 2016.

[43] D. Liu and R. F. Baumeister, "Social networking online and personality of self-worth: A meta-analysis, " Journal of Research in Personality, vol. 64, pp. 79-89, 2016.

[44] J.-L. Wang, H.-Z. Wang, J. Gaskin and S. Hawk, "The Mediating Roles of Upward Social Comparison and Selfesteem and the Moderating Role of Social Comparison Orientation in the Association between Social Networking Site Usage and Subjective Well-Being," Frontiers in Psychology, vol. 8, no. 771, 2017.

[45] A. L. Forest and J. V. Wood, "When social networking is not working: Individuals with low self-esteem recognize but do not reap the benefits of self-disclosure on Facebook," Psychological Science, vol. 23, pp. 295-302, 2012.

[46] A. L. Gonzales and J. T. Hancock, "Mirror, mirror on my Facebook wall: Effects of exposure to Facebook on selfesteem," Cyberpsychology, Behaviour, and Social Networking, vol. 14, no. 1-2, pp. 79-83, 2010.

[47] K. Wilcox and A. T. Stephen, "Are close friends the enemy? Online social networks, self-esteem, and self-control," Journal of Consumer Research, vol. 40, no. 1, pp. 90-103, 2012.

[48] T. F. Heatherton and J. Polivy, "Development and validation of a scale for measuring state self- esteem," Journal of Personality and Social Psychology, vol. 60, no. 6, pp. 895-910, 1991.

[49] M. Leary, "Making Sense of Self-Esteem," Current Directions In Psychological Science, vol. 8, no. 1, pp. 32-35, 1999.

[50] F. Bozorgpour and A. Salimi, "State Self-Esteem, Loneliness and Life Satisfaction," Procedia-Social and Behavioural Sciences, vol. 69, pp. 2004-2008, 2012.

[51] L. Kirkpatrick and B. Ellis, "An evolutionary-psychological approach to self-esteem: Multiple domains and multiple functions," in Blackwell handbook of social psychology: Interpersonal processes, pp. 411-436, 2001.

[52] G. Elliott, S. Kao and A. Grant, "Mattering: Empirical Validation of a Social-Psychological Concept," Self and Identity, vol. 3, no. 4, pp. 339-354, 2004.

[53] S. Marshall, "Do I Matter? Construct validation of adolescents' perceived mattering to parents and friends," Journal of Adolescence, vol. 24, no. 4, pp. 473-490, 2001.

[54] S. Schieman and J. Taylor, "Statuses, Roles, and the Sense of Mattering," Sociological Perspectives, vol. 44, no. 4, pp. 469-484, 2001.

[55] R. Taylor and J. Turner, "A longitudinal study of the role and significance of mattering to others for depressive symptoms," Journal of Health and Social Behaviour, vol. 42, no. 3, pp. 310-325, 2001.

[56] G. Flett, A. Khan and C. Su, "Mattering and Psychological Well-being in College and University Students: Review and Recommendations for Campus-Based Initiatives," International Journal of Mental Health and Addiction, vol. 17, vol. 3, pp. 667-680, 2019.

[57] M. Rosenberg and B. McCullough, "Mattering: Inferred significance and mental health," Research in Community and Mental Health, vol. 2, pp. 163-182, 1981.

[58] M. Rosenberg, "Self-concept and psychological well-being in adolescence," in The development of self, Toronto, Canada, In R. L. Leahy (Ed.), pp. 205-246, 1985.

[59] A. Dixon Rayle, "Adolescent gender differences in mattering and wellness," Journal of Adolescence, vol. 28, no. 6, pp. 753-763, 2005. 
[60] U. K. Moksnes and G. A. Espnes, "Self-esteem and life satisfaction in adolescents-gender and age as potential moderators," Quality of Life Research, vol. 22, no. 10, pp. 2921-2928, 2013.

[61] M. Demir, A. Özen, A. Doğan, N. Bilyk and F. Tyrell, "I Matter to My Friend, Therefore I am Happy: Friendship, Mattering, and Happiness," Journal of Happiness Studies, vol. 12, no. 6, pp. 983-1005, 2010.

[62] R. Y. Erol and U. Orth, "Self-esteem development from age 14 to 30 years: A longitudinal study," Journal of Personality and Social Psychology, vol. 101, no. 3, pp. 607-619, 2011.

[63] U. Orth, R. W. Robins and K. F. Widaman, "Life-span development of self-esteem and its effects on important life outcomes," Journal of Personality and Social Psychology, vol. 102, no. 6, pp. 1271-1288, 2012.

[64] B. Foroughi, M. Iranmanesh, D. Nikbin and S. Hyun, "Are depression and social anxiety the missing link between Facebook addiction and life satisfaction? The interactive effect of needs and self-regulation," Telematics and Informatics, vol. 43, pp. 101-247, 2019.

[65] M. Kolosnitsyna, N. Khorkina and H. Dorzhiev, "Determinants of Life Satisfaction in Older Russians," Ageing International, vol. 42, no. 3, pp. 354-373, 2017.

[66] A. Akin and U. Akin, "The Mediating Role of Social Safeness on the Relationship between Facebook® Use and Life Satisfaction," Psychological Reports, vol. 117, no. 2, pp. 341-353, 2015.

[67] Y. Tu and S. Zhang, "Loneliness and Subjective Well-Being among Chinese Undergraduates: The Mediating Role of Self-Efficacy," Social Indicators Research, vol. 124, no. 3, pp. 963-980, 2014.

[68] S. Satici, "Facebook Addiction and Subjective Well-Being: a Study of the Mediating Role of Shyness and Loneliness," International Journal of Mental Health and Addiction, vol. 17, no. 1, pp. 41-55, 2019.

[69] J. Zhao, F. Kong and Y. Wang, "Shyness and Subjective Well-being: The Role of Emotional Intelligence and Social Support," Social Indicators Research, vol. 114, no. 3, pp. 891-900, 2013.

[70] Y. Ngoo, N. Tey and E. Tan, "Determinants of Life Satisfaction in Asia," Social Indicators Research, vol. 124, no. 1, pp. 141-156, 2015.

[71] D. Kuss and M. Griffiths, "Online Social Networking and Addiction-A Review of the Psychological Literature," International Journal of Environmental Research and Public Health, vol. 8, no. 9, pp. 3528-3552, 2011.

[72] D. A. de Vries and R. Kühne, "Facebook and self-perception: individual susceptibility to negative social comparison on Facebook," Personality and Individual Differences, vol. 86, pp. 217-221, 2015. 